\title{
Extracorporeal membrane oxygenation in pediatric lung transplantation
}

\author{
Varun Puri, MD, ${ }^{a}$ Deirdre Epstein, RN, ${ }^{\text {a }}$ Steven C. Raithel, BS, ${ }^{\text {a }}$ Sanjiv K. Gandhi, MD, ${ }^{\text {a }}$ \\ Stuart C. Sweet, MD, ${ }^{\mathrm{b}}$ Albert Faro, MD, ${ }^{\mathrm{b}}$ and Charles B. Huddleston, MD ${ }^{\mathrm{a}}$
}

Objective: Effectiveness of preoperative and postoperative extracorporeal membrane oxygenation support in pediatric lung transplantation was studied.

Methods: Institutional database of pediatric lung transplants from 1990 to 2008 was reviewed.

\begin{abstract}
Results: Three hundred forty-four patients underwent lung transplants in the study period. Thirty-three of 344 patients $(9.6 \%)$ required perioperative extracorporeal membrane oxygenation support. Fifteen patients (median, age 1.3 years; range, $0.2-18$ years) required 16 pretransplant extracorporeal membrane oxygenation runs. Indications were respiratory failure $(8 / 16,50 \%)$, severe pulmonary hypertension $(5 / 16,31 \%)$, and cardiopulmonary collapse $(3 / 16,19 \%)$. Four of these patients $(27 \%)$ also required postoperative support. Six $(40 \%)$ were weaned before lung transplant. Six $(40 \%)$ survived to hospital discharge. Survival to discharge was higher among patients weaned before lung transplant $(4 / 6,66 \%$ vs $2 / 9,22 \%)$. Twenty-two patients (median age, 9.4 years; range, $0.2-$ 21 years) underwent 24 extracorporeal membrane oxygenation runs after lung transplant. Indications for postoperative support were primary graft dysfunction $(18 / 24,75 \%)$, pneumonia $(4 / 24,16 \%)$, and others $(2 / 24,9 \%)$. Median time between lung transplant and institution of extracorporeal membrane oxygenation was 32 hours (range, 0-1084 hours); median duration of support was 141 hours (range, 48-505 hours). Five of these patients $(23 \%)$ survived to hospital discharge. Among nonsurvivors, causes of death were intractable respiratory failure $(12 / 17,70 \%)$ and infectious complications $(4 / 17,24 \%)$.
\end{abstract}

Conclusions: Need for perioperative extracorporeal membrane oxygenation support is associated with significant morbidity and mortality among pediatric patients receiving lung transplants. A subset of patients who can be weaned from support preoperatively have greater likelihood of survival. (J Thorac Cardiovasc Surg 2010;140:427-32)

Lung transplants now provide well-accepted therapy for end-stage lung disease in both children and adults. Primary graft dysfunction (PGD) is the leading cause of early mortality after lung transplant. ${ }^{1}$ Despite improvements in surgical and preservation techniques, PGD is common after lung transplants, and severe PGD occurs in $13 \%$ to $35 \%$ of patients. $^{2}$

The severity of PGD and its attendant effects on other organ systems dictate therapy. Treatment may range from observation alone to extracorporeal membrane oxygenation (ECMO) support. Several series from leading transplant centers have described their experience with extracorporeal support in the postoperative period for adult patients and have shown acceptable outcomes. ${ }^{3-9}$ A recent review of the

From the Division of Cardiothoracic Surgery ${ }^{\mathrm{a}}$ and Department of Pediatrics, ${ }^{\mathrm{b}}$ Washington University in St Louis, St Louis, Mo.

Disclosures: None.

Read at the Eighty-ninth Annual Meeting of The American Association for Thoracic Surgery, Boston, Mass, May 9-13, 2009.

Received for publication May 12, 2009; revisions received Jan 18, 2010; accepted for publication April 10, 2010; available ahead of print June 10, 2010.

Address for reprints: Charles B. Huddleston, MD, Professor of Surgery, Washington University School of Medicine, Department of Surgery, 660 S Euclid Ave, Campus

Box 8234, St Louis, MO 63110 (E-mail: huddleston@wudosis.wustl.edu).

$0022-5223 / \$ 36.00$

Copyright (C) 2010 by The American Association for Thoracic Surgery

doi:10.1016/j.jtcvs.2010.04.012
Extracorporeal Life Support Organization registry showed 151 cases, with a $42 \%$ rate of survival to hospital discharge. ${ }^{9}$ There is, however, only a small body of evidence regarding the use of ECMO in pediatric patients in the posttransplant setting. ${ }^{10}$

Patients awaiting a lung transplant may require respiratory support, which may range from mechanical ventilation to ECMO support. Reports on the use of ECMO as a bridge to lung transplant are isolated, ${ }^{11,12}$ and the outcomes remain mixed. ${ }^{10-12}$ Many centers have considered ECMO to be a contraindication to lung transplant. Again, there are few data on outcomes among pediatric patients who require extracorporeal support while awaiting a lung transplant. ${ }^{10}$

We initiated a pediatric lung transplant program at our center in 1990. We describe here our experience with the use of preoperative and postoperative ECMO support for patients receiving lung transplants.

\section{MATERIALS AND METHODS \\ Operative Management}

In general, the transplant techniques have been consistent through time and operations were performed as previously described. ${ }^{13,14}$ Virtually all the operations were performed with cardiopulmonary bypass because of the difficulties of double-lumen endotracheal tube use in children and the prevalence of pulmonary hypertension in the pediatric cohort. 


\section{Abbreviations and Acronyms \\ $\mathrm{ECMO}=$ extracorporeal membrane oxygenation \\ PGD = primary graft dysfunction}

\section{ECMO Support}

A standardized ECMO perfusion circuit was used, with appropriately sized cannulas for patient size. The venoarterial configuration was used for all but 1 patient, who was placed on venovenous ECMO support. Transcervical cannulation was used for most patients who required ECMO before lung transplant. Typically, the right carotid artery and internal jugular veins were used. If transthoracic cannulation was used, the aorta and right atrium were cannulated. Among patients who required ECMO support after lung transplantation, transthoracic cannulation was used for patients who required support during the immediate postoperative period, whereas transcervical cannulation was preferred for patients with delayed presentation.

Pump flows were regulated on the basis of systemic perfusion, oxygenation, and mixed venous oxygenation. Pharmacologic support was weaned as tolerated, and patients were maintained with prophylactic antibiotics to cover gram-positive organisms unless culture-directed antibiotic coverage was indicated.

ECMO support was continued until one of the following end points was achieved: recovery of function sufficient to support stable oxygenation, gas exchange, and hemodynamics; availability of a transplant organ; or development of complications rendering the patient a noncandidate for transplant or recovery. There was no preset time limit for ECMO support.

\section{Postoperative Management}

In general, routine postoperative management was consistent during the period analyzed and has been described elsewhere. ${ }^{15}$

\section{Patients}

This single-center retrospective study examined outcomes of lung transplants among children who required ECMO support in the preoperative or postoperative period. An electronic database was queried to obtain data regarding the indications for and outcomes of all lung transplants performed between 1990 and 2008 at St Louis Children's Hospital at Washington University. Individual patient records were consulted to verify missing, incomplete or suspect data. The patients in this report include all patients that underwent deceased donor or living donor lung transplantation at Children's Hospital from 1990 through 2008. Institutional review board approval was obtained for the study, and need for individual patient consent was waived because of the minimal risk posed by the retrospective nature of the study.

\section{Statistics}

For this retrospective review, data are expressed as means unless otherwise stated. Descriptive statistics are presented, because the small numbers in the ECMO group preclude meaningful statistical comparisons between the groups.

\section{RESULTS}

Three hundred forty-four patients received lung transplants during the study period. Thirty-three of these 344 patients $(9.6 \%)$ required ECMO support in the perioperative period.

Fifteen patients (median age, 1.3 years; range, 0.2-18 years) required $16 \mathrm{ECMO}$ runs in the pretransplant period. Their diagnoses were as follows: pulmonary hypertension $(\mathrm{n}=4)$, surfactant deficiency $(\mathrm{n}=3)$, graft failure $(n=3)$, congenital diaphragmatic hernia $(n=2)$, pulmonary vein obstruction $(n=2)$, and cystic fibrosis $(n=1)$. The indications for ECMO were respiratory failure in 8 of 16 cases $(50 \%)$, severe pulmonary hypertension in 5 of $16(31 \%)$, and cardiopulmonary collapse in 3 of $16(19 \%)$. Vascular access was venoarterial $(16 / 16,100 \%)$, with neck vessels the preferred cannulation site $(14 / 16,87 \%)$.

Median duration of ECMO support was 234 hours (range, 8-576 hours). All patients survived through lung transplant, and 4 of $15(27 \%)$ required postoperative ECMO support as well. Six of 15 patients $(40 \%)$ ) were weaned from ECMO before lung transplant. Complications (sepsis, reexploration, and massive bleeding) were seen in 10 of 16 ECMO runs $(63 \%)$.

Six of 15 patients with preoperative ECMO support $(40 \%)$ survived to hospital discharge. Survival to discharge was higher among patients weaned from ECMO before lung transplant $(4 / 6,66 \%)$ than among patients still receiving ECMO support at lung transplant $(2 / 9,22 \%)$. None of the patients who required both preoperative and postoperative ECMO support $(\mathrm{n}=4)$ survived to hospital discharge. In addition, none of the 3 patients receiving reoperative lung transplants survived to hospital discharge.

Of the 6 patients in the preoperative ECMO group who were discharged from the hospital, 5 survived to 1 year and the other died of infectious complications at 261 days. Table 1 shows the characteristics of the patients with preoperative ECMO support versus the general transplant population without preoperative ECMO support. Table 2 compares the survivors and nonsurvivors in the preoperative ECMO support group. The number of patients is too small for meaningful statistical comparisons. The nonsurvivors in the preoperative ECMO group were older than the survivors because of inclusion of a patient with cystic fibrosis and 3 patients receiving reoperative lung transplants among the nonsurvivors.

Twenty-two patients (median age, 9.4 years; range, $0.2-$ 18 years) underwent 24 ECMO runs after lung transplant (Table 3). Their diagnoses were as follows: cystic fibrosis $(\mathrm{n}=6)$, pulmonary hypertension $(\mathrm{n}=5)$, bronchiolitis obliterans $(\mathrm{n}=4)$, and others $(\mathrm{n}=7)$. The indications for ECMO support were primary graft dysfunction in 18 of 24 cases $(75 \%)$, pneumonia in 4 of $24(16 \%)$, and others in 2 of $24(9 \%)$. The median time between lung transplant and institution of ECMO was 141 hours (range, 48-505 hours). The median time was 660 hours for patients who required ECMO for pneumonia.

Access was predominantly venoarterial $(23 / 24,96 \%)$, and mean duration of ECMO support was $158 \pm 125$ hours. Central cannulation in the chest was used in 15 of 24 ECMO runs $(62.5 \%)$. Major complications were seen in $82 \%$ of patients. Five of 22 patients $(23 \%)$ survived to hospital discharge (median survival, 5.8 years). Among the nonsurvivors, the 
TABLE 1. Comparison of patients who needed extracorporeal membrane oxygenation before lung transplant with those who did not

\begin{tabular}{|c|c|c|}
\hline & \multicolumn{2}{|c|}{ Pretransplant ECMO } \\
\hline & Yes & No \\
\hline No. of transplants & 15 & 329 \\
\hline No. of preoperative ECMO runs & 16 & 0 \\
\hline Age $(y$, median and range $)$ & $1.3(0.2-18)$ & $11(0.2-18)$ \\
\hline Sex (female/male) & $10: 5$ & 180:149 \\
\hline \multicolumn{3}{|l|}{ Diagnoses (no.) } \\
\hline Pulmonary hypertension & $4(27 \%)$ & $54(16 \%)$ \\
\hline Surfactant deficiency & $3(20 \%)$ & 0 \\
\hline Graft failure & $3(20 \%)$ & $41(12 \%)$ \\
\hline Congenital diaphragmatic hernia & $2(13 \%)$ & 0 \\
\hline Pulmonary vein obstruction & $2(13 \%)$ & $13(4 \%)$ \\
\hline Cystic fibrosis & $1(7 \%)$ & $166(51 \%)$ \\
\hline Interstitial pneumonia or fibrosis & 0 & $34(10 \%)$ \\
\hline Other & 0 & $21(7 \%)$ \\
\hline Single/double transplant ratio & $2: 13$ & $7: 322$ \\
\hline ICU stay (d, median and range) & $46(0-88)$ & $7(0-164)$ \\
\hline Hospital stay (d, median and range) & $46(8-96)$ & $19(1-261)$ \\
\hline \multicolumn{3}{|l|}{ Ischemic time (min, median and range) } \\
\hline Left & 290 & 254 \\
\hline Right & 315 & 305 \\
\hline Postoperative ECMO (no.) & $4 / 15(27 \%)$ & $18 / 329(5.5 \%)$ \\
\hline Major complications* (no.) & $10 / 16(63 \%)$ & $91 / 329(27.6 \%)$ \\
\hline Survival to discharge (no.) & $6 / 15(40 \%)$ & $295 / 329(89.7 \%)$ \\
\hline Survival at $1 \mathrm{y}$ (no.) & $5 / 15(33 \%)$ & $264 / 329(80.2 \%)$ \\
\hline
\end{tabular}

$E C M O$, Extracorporeal membrane oxygenation; $I C U$, intensive care unit. *Major complications were bleeding, stroke, reexploration, and infection.

causes of death were intractable respiratory failure (12/17, $70 \%$ ) and infectious complications (4/17, 24\%; Table 4). There were 18 patients who required ECMO support for PGD. In this group, the median time between lung transplant and institution of ECMO for PGD was 5 hours (range, 0-24 hours) for the 4 survivors and 40 hours (range, $0-408 \mathrm{~h}$ ) for the 14 non-survivors.

\section{DISCUSSION}

Main findings of our retrospective review are that children who require ECMO support before or after lung transplantation have both high incidence of major morbidity and high mortality. Kirshbom and colleagues ${ }^{10}$ reviewed their use of ECMO in the perioperative setting in pediatric thoracic organ transplantation and described major complication rates of $60 \%$ and $55 \%$ in their pretransplant and posttransplant ECMO groups, respectively. Our incidences of major complications (bleeding, reexploration, major infection, and stroke) in the preoperative and postoperative setting were $63 \%$ and $82 \%$, respectively.

There have been sporadic reports about use of ECMO as a bridge to lung transplant. ${ }^{11,12}$ Jackson and coworkers ${ }^{11}$ reported 3 of their own cases, all with successful bridging to lung transplant, and summarized previous reports to show
TABLE 2. Comparison of survivors and nonsurvivors among patients who required extracorporeal membrane oxygenation before lung transplant

\begin{tabular}{lcc}
\hline & Survivors & Nonsurvivors \\
\hline No. of transplants & 6 & 9 \\
Age (y, median and range) & $0.73(0.2-1.8)$ & $1.1(0.1-10.2)$ \\
Sex (female/male) & $4: 2$ & $6: 3$ \\
Diagnoses (no.) & & \\
$\quad$ Pulmonary hypertension $(\mathrm{n}=4)$ & $2(33 \%)$ & $2(18 \%)$ \\
$\quad$ Surfactant deficiency $(\mathrm{n}=3)$ & $2(33 \%)$ & $1(11 \%)$ \\
$\quad$ Graft failure $(\mathrm{n}=3)$ & 0 & $3(33 \%)$ \\
$\quad$ Congenital diaphragmatic & $1(17 \%)$ & $1(11 \%)$ \\
$\quad$ hernia (n $=2)$ & $1(17 \%)$ & $1(11 \%)$ \\
$\quad$ Pulmonary vein obstruction (n $=2)$ & 0 & $1(11 \%)$ \\
$\quad$ Cystic fibrosis (n $=1)$ & $4(66 \%)$ & $2(18 \%)$ \\
Weaning from ECMO before & & \\
$\quad$ transplant (no.) & $281(8-576)$ & $227(24-405)$ \\
Duration of ECMO (h, median & & \\
$\quad$ and range) & $43(11-90)$ & $26.5(7-110)$ \\
ICU stay (d, median and range) & $46(21-118)$ & $39(7-118)$ \\
Hospital stay (d, median and range) & & \\
Ischemic time (min, median and range) & & 272 \\
$\quad$ Left & 328 & 285 \\
Right & $0(0 \%)$ & $4(44 \%)$ \\
Posttransplant ECMO & &
\end{tabular}

$E C M O$, Extracorporeal membrane oxygenation; $I C U$, intensive care unit.

a 1-year survival of about $40 \%$ for ECMO as a bridge to lung transplant in the adult population. Our 1-year survival in a similar setting with use of preoperative ECMO in a pediatric population was $33 \%$. These numbers are significantly lower than our 1-year survival of $80 \%$ in the general pediatric lung transplant population without preoperative ECMO.

We were able to wean 6 of 15 patients $(40 \%)$ from ECMO in the preoperative setting, so technically these patients were not bridged to lung transplant. It is in this population that we saw our best outcomes, however, with 4 of these 6 patients surviving to 1 year. Of the 9 patients still supported by ECMO at the time of lung transplant, only $2(18 \%)$ survived to 1 year. Of the 2 survivors, 1 was given ECMO support for only 8 hours, and lungs were already available at the time, whereas the other survivor received ECMO for 24 days before lung transplant. On the basis of our suboptimal outcomes for patients supported by ECMO while awaiting a lung transplant, our current practice is to delist patients with respiratory failure when ECMO is instituted.

It may appear from our report that all our patients listed for lung transplant who needed preoperative ECMO support received lung transplants. This is not the case, however, because this study selectively examined patients who received lung transplants at our center, and the true denominator would be the total number of patients with intractable respiratory failure who received ECMO support. During the study period, 23 patients with intractable respiratory failure were given ECMO support and placed on the lung transplant 
TABLE 3. Comparison of patients who needed extracorporeal membrane oxygenation after lung transplant with those who did not

\begin{tabular}{lcc}
\hline & \multicolumn{2}{c}{ Posttransplant ECMO } \\
\cline { 2 - 3 } & Yes & No \\
\hline No. of transplants & 22 & 322 \\
Age (y, median and range) & $8.2(1-21)$ & $12.1(0.1-18)$ \\
Sex (female/male) & $13: 9$ & $177: 145$ \\
Diagnoses (no.) & & \\
$\quad$ Cystic fibrosis & $6(27 \%)$ & $161(50 \%)$ \\
$\quad$ Pulmonary hypertension & $5(23 \%)$ & $53(17 \%)$ \\
$\quad$ Bronchiolitis obliterans & $4(18 \%)$ & $40(12 \%)$ \\
$\quad$ Pulmonary fibrosis & $2(9 \%)$ & $32(10 \%)$ \\
$\quad$ Adult respiratory distress syndrome & $2(9 \%)$ & 0 \\
Other & $3(13 \%)$ & $36(11 \%)$ \\
Single/double transplant ratio & $2: 20$ & $7: 315$ \\
ICU stay (d, median and range) & $14(3-88)$ & $7(0-164)$ \\
Hospital stay (d, median and range) & $17(3-145)$ & $19(1-261)$ \\
Ischemic time (min, median and range) & \multicolumn{2}{c}{} \\
$\quad$ Left & 271 & 254 \\
$\quad$ Right & 281 & 385 \\
Major complications* (no.) & $18(82 \%)$ & $83(26 \%)$ \\
Survival to discharge (no.) & $5(23 \%)$ & $296(92 \%)$ \\
Survival at 1 y (no.) & $4(18.2 \%)$ & $265(82.3 \%)$ \\
\hline ECMO, Extracorporeal membrane oxygenation; $I C U$, intensive care unit. *Major \\
complications were bleeding, stroke, reexploration, and infection.
\end{tabular}

list. Eventually, 15 of these patients underwent lung transplant, whereas the remaining 8 patients died before lung transplant. In a report from Kirshbom and colleagues, ${ }^{10} 8$ children were given ECMO support in an attempt to bridge to lung transplant. None of these patients survived to lung transplant or discharge after a mean ECMO run of 588 hours. This highlights the problem of demand-supply mismatch in pediatric lung transplantation and emphasizes the importance of patient selection when considering the use of ECMO in the pretransplant setting. Children younger than 12 years are not prioritized by the Lung Allocation Score system used for older children and adults. A child older than 12 years would predictably have a higher Lung Allocation Score and thus get offers in a more timely fashion than an infant.

An interesting recent development has been the use of newer lung replacement technologies. The interventional lung assist NovaLung (iLA; NovaLung GmbH, Hechingen, Germany) is a low-resistance lung assist device designed for pulsatile blood flow with tight diffusion membranes and a protein matrix coating. ${ }^{16}$ It is driven by the cardiac output and therefore does not require extracorporeal pump assistance. The Hannover group ${ }^{17}$ described 12 patients with isolated hypercapnic respiratory failure who were supported with this device; of these, 10 were successfully bridged to lung transplant. At 1 year, 8 patients were alive. ${ }^{17}$ Since then, Fischer and associates ${ }^{18}$ from Hannover have combined this device with a pump and used it for both hypercapnic and hypoxic respiratory failure in the pretransplant
TABLE 4. Comparison of survivors and nonsurvivors among patients who required extracorporeal membrane oxygenation after lung transplant

\begin{tabular}{|c|c|c|}
\hline & Survivors & Nonsurvivors \\
\hline No. of patients & 5 & 17 \\
\hline No. of ECMO runs & 6 & 18 \\
\hline Age (y, median and range) & $9.2(1.8-17)$ & $3.9(0.2-21)$ \\
\hline Sex (female/male) & $3: 2$ & $10: 7$ \\
\hline \multicolumn{3}{|l|}{ Diagnoses (no.) } \\
\hline Cystic fibrosis $(n=6)$ & $1(20 \%)$ & $5(29 \%)$ \\
\hline Pulmonary hypertension $(\mathrm{n}=5)$ & $2(40 \%)$ & $3(18 \%)$ \\
\hline Bronchiolitis obliterans $(n=4)$ & $1(20 \%)$ & $3(18 \%)$ \\
\hline Pulmonary fibrosis $(\mathrm{n}=2)$ & 0 & $2(12 \%)$ \\
\hline $\begin{array}{l}\text { Adult respiratory distress } \\
\text { syndrome }(\mathrm{n}=2)\end{array}$ & 0 & $2(12 \%)$ \\
\hline Other $(\mathrm{n}=3)$ & $1(20 \%)$ & $2(12 \%)$ \\
\hline Pretransplant ECMO (no.) & 0 & 4 \\
\hline $\begin{array}{l}\text { Postoperative ECMO duration } \\
\text { (h, median and range) }\end{array}$ & $91(48-408)$ & $152(25-505)$ \\
\hline ICU stay (d, median and range) & $40(3-41)$ & $14(8-74)$ \\
\hline Hospital stay (d, median and range) & $40(10-96)$ & $14(3-110)$ \\
\hline \multicolumn{3}{|l|}{ Ischemic time (min, median and range) } \\
\hline Left & 330 & 281 \\
\hline Right & 314 & 303 \\
\hline \multicolumn{3}{|l|}{ Indication for ECMO runs (no.) } \\
\hline Primary graft dysfunction $(\mathrm{n}=18)$ & 4 & 14 \\
\hline Pneumonia $(\mathrm{n}=4)$ & 2 & 2 \\
\hline Other $(\mathrm{n}=2)$ & 0 & 2 \\
\hline
\end{tabular}

setting. The use of the NovaLung device has not been described in the pediatric population.

ECMO support has been used more commonly after lung transplant. Several series describe 1-year survivals ranging from $26 \%$ to $47 \%$ when ECMO support is used (predominantly for PGD) in the adult population. ${ }^{3-5,7,8,19}$ Kirshbom and colleagues ${ }^{10}$ reported a cohort of 8 children requiring ECMO support after lung or heart-lung transplants with an encouraging hospital discharge rate of $63 \%$. Our own hospital discharge rate for posttransplant ECMO support was 5 of $18(28 \%)$ after exclusion of patients already supported by ECMO before lung transplant. Mason and coworkers ${ }^{5}$ from the Cleveland Clinic reported 1-year survivals of $41 \%$ with ECMO for PGD but only 3\% with ECMO support for posttransplant pneumonia or sepsis. In our series, of the 6 ECMO runs in patients who survived to hospital discharge, 4 were for PGD and 2 for pneumonia. This may have been due to chance, because the numbers involved were small, or it may represent a difference between the adult and pediatric populations.

Hartwig and associates ${ }^{6}$ reported superior outcomes after venovenous ECMO versus venoarterial ECMO for posttransplant PGD. In their experience comparing venoarterial with venovenous cannulation, they reported a 30-day survival of $88 \%$ in the venovenous group $(\mathrm{n}=8)$, as opposed 
no 30-day survival in the venoarterial cohort $(n=15)$. They also noted that the venoarterial group had 30 severe complications, compared with 9 complications in the venovenous group. For children who require ECMO support for respiratory reasons, the venoarterial mode is often used with concerns about hemodynamic instability developing from respiratory failure. We used venovenous ECMO on 1 occasion recently for posttransplant pneumonia, and the patient is alive at 10 months. We are now more likely to use the venovenous configuration in the appropriate clinical setting.

Interestingly, we noted that the mean time for institution of ECMO for PGD after lung transplant was shorter for the 4 survivors than for the 14 nonsurvivors ( 8.5 hours vs 75 hours). Although the number of patients was small, this may indicate that patients who are supported with ECMO earlier may do better than patients who are treated with longer periods of more aggressive ventilatory strategies before resorting to ECMO. We are now more likely to consider earlier institution of ECMO rather than persisting with aggressive ventilatory strategies in managing severe PGD.

\section{CONCLUSIONS}

The need for perioperative ECMO support is associated with significant morbidity and mortality in the pediatric lung transplant population. A subset of patients who can be weaned from ECMO in the preoperative setting have greater likelihood of survival. Extracorporeal support should be cautiously offered to children with intractable respiratory failure who are awaiting a primary (not reoperative) lung transplant and to children with severe PGD or pneumonia after lung transplant for whom more conservative therapy does not work. Earlier institution of ECMO for severe PGD may possibly be protective.

\section{References}

1. Boucek MM, Edwards LB, Keck BM, Trulock EP, Taylor DO, Hertz MI. Registry of the International Society for Heart and Lung Transplantation: eighth official pediatric report-2005. J Heart Lung Transplant. 2005;24:968-82.

2. Lee CJ. Intensive cardiopulmonary support for otherwise dying post-heart and lung transplant recipients with extracorporeal membrane oxygenation. Artif Organs. 2001;25:597-8

3. Oto T, Rosenfeldt F, Rowland M, Pick A, Rabinov M, Preovolos A, et al. Extracorporeal membrane oxygenation after lung transplantation: evolving technique improves outcomes. Ann Thorac Surg. 2004;78:1230-5.

4. Meyers BF, Sundt TM 3rd, Henry S, Trulock EP, Guthrie T, Cooper JD, et al. Selective use of extracorporeal membrane oxygenation is warranted after lung transplantation. J Thorac Cardiovasc Surg. 2000;120:20-6.

5. Mason DP, Boffa DJ, Murthy SC, Gildea TR, Budev MM, Mehta AC, et al. Extended use of extracorporeal membrane oxygenation after lung transplantation. J Thorac Cardiovasc Surg. 2006;132:954-60.

6. Hartwig MG, Appel JZ 3rd, Cantu E 3rd, Simsir S, Lin SS, Hsieh CC, et al. Improved results treating lung allograft failure with venovenous extracorporeal membrane oxygenation. Ann Thorac Surg. 2005;80:1872-80.

7. Bermudez CA, Adusumilli PS, McCurry KR, Zaldonis D, Crespo MM, Pilewski JM, et al. Extracorporeal membrane oxygenation for primary graft dysfunction after lung transplantation: long-term survival. Ann Thorac Surg. 2009; 87:854-60.

8. Dahlberg PS, Prekker ME, Herrington CS, Hertz MI, Park SJ. Medium-term results of extracorporeal membrane oxygenation for severe acute lung injury after lung transplantation. J Heart Lung Transplant. 2004;23:979-84.
9. Fischer S, Bohn D, Rycus P, Pierre AF, de Perrot M, Waddell TK, et al. Extracorporeal membrane oxygenation for primary graft dysfunction after lung transplantation: analysis of the Extracorporeal Life Support Organization (ELSO) Registry. J Heart Lung Transplant. 2007;26:472-7.

10. Kirshbom PM, Bridges ND, Myung RJ, Gaynor JW, Clark BJ, Spray TL. Use of extracorporeal membrane oxygenation in pediatric thoracic organ transplantation. J Thorac Cardiovasc Surg. 2002;123:130-6.

11. Jackson A, Cropper J, Pye R, Junius F, Malouf M, Glanville A. Use of extracorporeal membrane oxygenation as a bridge to primary lung transplant: 3 consecutive, successful cases and a review of the literature. J Heart Lung Transplant. 2008;27:348-52.

12. Hämmäinen P. Re: Use of extracorporeal membrane oxygenation as a bridge to primary lung transplant: 3 consecutive, successful cases and a review of the literature [letter]. J Heart Lung Transplant. 2008;27:1186.

13. Huddleston C, Bloch JB, Sweet SC, de la Morena M, Patterson GA, Mendeloff EN. Lung transplantation in children. Ann Surg. 2002;236:270-6.

14. Mendeloff EN. Donor selection, organ preservation, surgical technique and perioperative management. In: Tejani AH, Harmon WE, Fine RN, eds. Pediatric solid organ transplantation. 1st ed. Copenhagen: Munksgaard; 2000. p. 471-81.

15. Elizur A, Faro A, Huddleston CB, Gandhi SK, White D, Kuklinski CA, et al. Lung transplantation in infants and toddlers from 1990 to 2004 at St. Louis Children's Hospital. Am J Transplant. 2009;9:719-26.

16. Matheis G. New technologies for respiratory assist. Perfusion. 2003;18:245-51.

17. Fischer S, Simon AR, Welte T, Hoeper MM, Meyer A, Tessmann R, et al. Bridge to lung transplantation with the novel pumpless interventional lung assist device NovaLung. J Thorac Cardiovasc Surg. 2006;131:719-23.

18. Fischer S, Hoeper MM, Tomaszek S, Simon A, Gottlieb J, Welte T, et al. Bridge to lung transplantation with the extracorporeal membrane ventilator NovaLung in the veno-venous mode: the initial Hannover experience. ASAIO J. 2007;53: 168-70.

19. Aigner C, Wisser W, Taghavi S, Lang G, Jaksch P, Czyzewski D, et al. Institutional experience with extracorporeal membrane oxygenation in lung transplantation. Eur J Cardiothorac Surg. 2007;31:468-73.

\section{Discussion}

Dr Victor Morell (Pittsburgh, $\mathrm{Pa}$ ). Dr Puri and associates presented their extensive experience with preoperative and postoperative ECMO support in their pediatric lung transplant population. I would have to admit that at Children's Hospital of Pittsburgh, we consider preoperative ECMO a contraindication for lung transplant; however, there is certainly adult literature that would support transplants for patients with ECMO support, and the results have been reasonable.

I have 3 questions, Dr Puri. With the limited availability of organs, what is the current management at your institution for patients with ECMO support? Are they still listed?

Dr Puri. The short answer is no, and our results reflect that. We had lower than $15 \%$ survival for patients supported by ECMO going into lung transplantation, and organs, as you say, are scarce. Therefore we delist the patients when they are supported by ECMO.

Dr Morell. The second question is, I was a little surprised at the poor outcome of postoperative ECMO, the patients who required ECMO after transplant. Do you have some insight into why such poor results with postoperative ECMO?

Dr Puri. Dr Morell, I take it that you are referring to a comparison between pediatric and adult literature?

Dr Morell. I mean, we don't have an extensive experience with postoperative ECMO either, but I would expect a higher survival among patients who only require postoperative ECMO if they were reasonable candidates before operation and received reasonable lungs. I just wonder, why do you think the survival was so poor for patients who required postoperative ECMO? 
Dr Puri. Just to put things into perspective, when the adult population requires postoperative ECMO, survivals range between $40 \%$ and $65 \%$, depending on the study. For our patients, the general perception was that if they required posttransplant ECMO, they were sicker patients going into the procedure. I believe that we have erroneously had a strategy of performing aggressive ventilatory strategies on freshly implanted lungs for longer periods, which is something that we have reversed recently. Finally, in this particular patient population, there are somewhat higher incidences of pulmonary hypertension and bronchiolitis obliterans than in the general transplant population, either pediatric or adult.

Dr Morell. I guess my final question is somewhat similar to that. About $6 \%$ of your patients required postoperative ECMO, and I'm just wondering whether you had a chance to look at any preoperative variables that might help to identify patients who might be at risk for postoperative ECMO.

Dr Puri. The combined incidence of bronchiolitis obliterans and pulmonary hypertension was somewhat higher in the ECMO group. It was $28 \%$ or so for the general population and $41 \%$ for this particular group.

Dr Morell. Thank you.

Dr Shaf Keshavjee (Toronto, Ontario, Canada). Dr Puri, am I to understand that you had 3 patients in the preoperative ECMO group with an indication of primary graft failure?

Dr Puri. One patient had primary graft failure and 2 patients had bronchiolitis obliterans. I grouped them together as having PGD.

Dr Keshavjee. So the patient with the primary graft failure would have been counted twice?

Dr Puri. Counted both in the preoperative and postoperative ECMO groups.

Dr Keshavjee. But in the postoperative ECMO group the first time around, and then the preoperative ECMO group, and then again in the postoperative ECMO group?

Dr Puri. Correct.
Dr Waleed Saleh (Riyadh, Saudi Arabia). You mentioned that if you started the ECMO early, the outcome was better than with a late start, and this is well documented in adult transplantation. Do you have criteria to start the ECMO?

Dr Puri. A number of parameters are looked at by the team taking care of patients: oxygenation, our ability to ventilate these lungs without excessive airway pressures, systemic hemodynamic compromise, and the trajectory of the clinical course in the few hours after transplantation. In our earlier experience, we did not have this insight, so we had long periods of using aggressive ventilatory strategies on these freshly implanted lungs. I think that was a bad idea, and we have recognized this lately and are moving further and further toward earlier institution of ECMO if we think the clinical trajectory is headed in the wrong direction.

Dr Saleh. Thank you. Nice article.

Dr Puri. Dr Keshavjee, may I solicit a comment from you?

Dr Keshavjee. Sure.

Dr Puri. I believe that you have the most extensive North American NovaLung program. Are there any pediatric NovaLung applications that you've had, Dr Keshavjee?

Dr Keshavjee. Yes. Well, the NovaLung can run from $0.5 \mathrm{~L}$ to $4.5 \mathrm{~L} / \mathrm{min}$, so it's capable of bridging kids to transplant. We have only used the NovaLung as opposed to the standard ECMO setup once, and we did it with the PA-to-LA setting. But I do think the technology is getting better. The one thing that has come up, we have all learned that in the posttransplant phase, if you're going to do it, just do it sooner. Every time we have regretted waiting longer, and we have had much smoother and shorter runs when we have put it on early, almost to the point where you wonder whether you could have gotten by without it. I think the most important take-home message is that in the posttransplant period, you should resort to it sooner than later, before you've got a very bad problem on your hands. 